\title{
O Enfermeiro frente às competências gerenciais na Gestão à Saúde: uma pesquisa bibliográfica
}

Andréia de Melo ${ }^{1}$; Sâmella dos Santos Vieira ${ }^{2}$

\begin{abstract}
Resumo: O presente estudo foi desenvolvido com o propósito de fornecer subsídios norteadores ao enfermeiro no âmbito da Gestão em Enfermagem, especialmente para os desafios lançados às suas competências gerenciais. Consiste em uma pesquisa de revisão bibliográfica do tipo exploratória, e abordagem qualitativa. O banco de dados utilizado foi a Revista Brasileira de Enfermagem, no período de 2004-2013, sendo o levantamento bibliográfico de artigos científicos feitos com base nos descritores: Administração em Recursos Humanos: Gestão; Competências Gerenciais. Foi possível observar que, apesar de o assunto em questão ter tomado uma percussão forte e um amplo espaço no mercado de trabalho, ainda existe uma dificuldade em definir com clareza as competências gerenciais do enfermeiro, mas as metas caminham para possibilidade de alcançarem melhores resultados correspondentes aos desafios da profissão e do mercado de trabalho.
\end{abstract}

Palavras-chave: Administração em Recursos Humanos: Gestão; Competências Gerenciais;

\section{The Nurse in the face of Competency Skills in Health Management: A Literature Search}

\begin{abstract}
The present study was developed with the purpose of providing grants to nurses whose guiding under the Nursing Management, especially for the challenges posed to their managerial skills . It consists of a literature review of research exploratory and qualitative approach. The database used was the Brazilian Journal of Nursing , from 2004-2013, and the literature of scientific articles made based on descriptors : Administration in Human Resources : Management; Management Skills. It was observed that, although the subject matter has taken a strong percussion and ample space in the labor market, there is a difficulty in defining clearly the nursing managerial skills, but the goals go to possibility to achieve better matching results the challenges of the profession and the labor market.
\end{abstract}

Keywords: Administration in Human Resources: Management; Management Skills

\section{Introdução}

As empresas estão cada vez mais preocupadas com sua ocupação e posição no mercado de trabalho, e tem investido fortemente em gestores. Segundo Furakawa e Cunha (2010), na área da saúde não é diferente, pois o grande avanço tecnológico e mercadológico vem motivando os enfermeiros a repensar o seu papel de liderança frente a sua equipe e a sua posição no mercado de trabalho.

Tais avanços buscam profissionais com perfis diferenciados, sendo o enfermeiro o gestor responsável em desempenhar suas atividades com responsabilidade no que diz respeito à assistência e a parte administrativa em todas as áreas de prestação de serviço da Saúde. Desta maneira, os enfermeiros precisam buscar constantemente conhecimentos que sustentem sua atuação gerencial em seu processo de trabalho (BALSANELLI et al, 2011).

\footnotetext{
${ }^{1}$ Universidade Federal Vale do São Francisco. Departamento de Enfermagem. CV: http://lattes.cnpq.br/7050544859555464. Contato: andrihenri@gmail.com;

${ }^{2}$ Universidade Federal Vale do São Francisco. CV: http://lattes.cnpq.br/0949174808482495. Contato: ${ }^{2}$ Samella.vieira@ hotmail.com.
} 
Para que o cuidado efetivo em saúde seja alcançada, Harada (2011) propõe que o profissional que exerce a gerência faça uso de instrumentos do trabalho administrativo como o planejamento, a organização, a coordenação e o controle. Estes profissionais devem ser dotados de conhecimentos (autoconhecimento, planejamento estratégico, sistematização da assistência de Enfermagem (SAE), custos, políticas de saúde, legislação de enfermagem, definição e solução de problemas, análise do ambiente); capacidades (técnicas); atitudes (formar e reter talentos, abertura a mudanças, integridade, comprometimento e envolvimento com seu trabalho e com a instituição, flexibilidade, sociabilidade, trabalho em equipe, postura e ética); e habilidades (administrar relacionamentos, construir e definir equipes, lidar com conflitos, negociar, interligar tarefas específicas com objetivos institucionais, reconhecer sua liderança).

Compete ainda ao enfermeiro gestor, gerir a qualidade da assistência à saúde, promover a existência de recursos humanos qualificados e recursos materiais compatíveis e adequados à oferta de cuidados de acordo com as necessidades de saúde.

Associada a uma menção de determinantes políticos e econômicos a saúde vem conquistando avanço em seu sistema produtor de serviços, e provocando mudanças na estrutura ocupacional de seus setores, ativando o perfil quantitativo e qualitativo da força de trabalho na saúde. A importante conquista na expansão da oferta de trabalho nesta área se revela ao dinamismo no mercado de trabalho.

Embora alguns dados revelem que mesmo com a implantação do SUS ainda tem maior destaque nos cargos ocupado os médicos, auxiliares e técnicos de enfermagem, nas três ultimas décadas o enfermeiro vem buscando fortemente sua classificação no mercado de trabalho, tendo como determinante para ampliar a diferença no campo de trabalho, maior conhecimento, dinamismo, atitudes, habilidades, poder de decisão, potencial de qualidade, competência e disciplina.

Estes novos modelos começaram a refletir, trazendo para o âmbito social e político da saúde conceitos de inovação, trabalho em equipe, flexibilidade e decisões descentralizadas e a partir destes novos conceitos, iniciou-se a busca por profissionais capazes de gerir caminhos que aprimore melhor desempenho organizacional administrativo e operacional da empresa, com participação ativa e efetiva de todos os envolvidos. Para tanto surge à possibilidade do enfermeiro gestor, desenvolver suas competências gerenciais, uma vez que suas competências ganham destaque pela desenvoltura de sua atuação e formação profissional.

\section{Objetivos}

O objetivo deste trabalho consiste em analisar a produção bibliográfica sobre gestão a saúde pelos enfermeiros, tendo como foco a compreensão de suas competências gerenciais. Esta pesquisa permitirá compreender quais os principais contextos de saúde que o enfermeiro incorpora como 
gestor, entender os sentidos e significados atribuídos em seu processo de gestão em saúde, descrever as competências gerenciais utilizadas e discutir a importância da gestão por competências no âmbito da atenção à saúde.

\section{Metodologia}

A pesquisa bibliográfica desenvolvida foi do tipo exploratória, qualitativa e descritiva (GIL, 2002). A pesquisa qualitativa pode ser definida como um estudo não estatístico, que identifica e analisa em profundidade dados de difícil mensuração de um determinado grupo de indivíduos em relação a um problema específico. Entre eles estão sentimentos, sensações e motivações que podem explicar determinados comportamentos, apreendidos com o foco no significado que adquirem.

Conforme Selltiz et al. (1987) e Trivinos (1987) a presente pesquisa, levando-se em conta o objetivo principal do trabalho, se caracteriza como exploratória e descritiva. Descritiva por se conduzir de forma a apresentar os dados exatamente da forma em que se encontram. Exploratória a partir do momento em que se pretende encontrar os elementos necessários que permitem, em contato com determinada população, obter os resultados desejados.

A pesquisa qualitativa proporciona compreensão em profundidade do contexto do problema. É um método indutivo por excelência para entender por que o indivíduo age como age, pensa como pensa ou sente como sente, pois, respostas em profundidade são geradas apenas pela abordagem qualitativa (MINAYO, 2004).

Para alcançar o objetivo deste estudo, utilizou-se a pesquisa bibliográfica de fonte secundária, como método. Para Cervo e Bervian (2002, p.65, 89), a pesquisa bibliográfica é desenvolvida a partir de material já elaborado, constituído principalmente, por livros e artigos científicos, além de textos divulgados por textos magnéticos e eletrônicos, procurando explicar um problema, a partir de referenciais teóricos publicados, tendo a intenção de recolher os conhecimentos a cerca de um problema, constituindo-se no processo básico para os estudos monográficos.

A fonte de coleta foi a Revista Brasileira de Enfermagem- REBEn, na sua versão online disponível na base de dados do Scielo. O recorte temporal foi de 2004 a 2013. A utilização da REBEn como base de coleta de dados se deu por ser um importante período da área de Enfermagem, tendo notoriedade na divulgação da produção científica no setor. Além disso, por questões de exequibilidade, optou-se pela escolha de apenas uma revista/periódico.

A título de contextualização, criada em 1932 a Revista Brasileira de Enfermagem (REBEn), é o órgão oficial de publicação da Associação Brasileira de Enfermagem (ABEn), sendo o mais antigo periódico da Enfermagem brasileira, tem como missão divulgar a produção científica das 
diferentes áreas do saber que sejam do interesse da Enfermagem, inclusive a que expresse o projeto político da Associação.

Teve seu primeiro título como "Annaes de Enfermagem", de maio de 1932 a abril de 1941, modificado para "Anais de Enfermagem", de janeiro de 1946 a dezembro de 1954, logo passou a ter o título atual - Revista Brasileira de Enfermagem (REBEn). Sua periodicidade é bimestral, realiza uma tiragem atual de 800 exemplares por fascículo. Sua distribuição consiste regularmente aos assinantes; a bibliotecas de instituições de ensino com Programas de Pós-Graduação e Cursos de Graduação em Enfermagem; e a Instituições / Serviços de Saúde, por meio de permutas e doações

A principio, foram utilizados descritores de forma livre, o que não resultou em êxito na consulta no site da REBEn. Ao refinar a busca em campo específico do site, encontramos os seguintes descritores: administração em recursos humanos; gestão; e competências gerencias.

Para fins de coleta de dados, foram elencados os trabalhos que se referiam a artigos de revisão, por considerar que os mesmos possuem elementos conceituais importantes para o subsídio teórico na prática de gestão do enfermeiro no contexto hospitalar, tanto de serviços de saúde públicos quanto privados. Assim, 4 artigos puderam se enquadrar nos requisitos supracitados.

\section{Resultados e Discussão}

Figura 1. Características gerais das referências

\begin{tabular}{|c|c|c|c|}
\hline TÍTULO & MÉTODO & ANO & ARTIGO \\
\hline $\begin{array}{l}\text { Entendendo as } \\
\text { competências para } \\
\text { aplicação na } \\
\text { enfermagem }\end{array}$ & $\begin{array}{l}\text { Revisão Integrativa da } \\
\text { Literatura }\end{array}$ & 2007 & Reflexão \\
\hline $\begin{array}{l}\text { Competências do } \\
\text { enfermeiro na gestão } \\
\text { do conhecimento e } \\
\text { capital intelectual }\end{array}$ & Pesquisa Bibliográfica & 2009 & Revisão \\
\hline $\begin{array}{l}\text { Da Gestão por } \\
\text { Competências as } \\
\text { Competências } \\
\text { Gerenciais do } \\
\text { Enfermeiro } \\
\end{array}$ & Revisão Bibliográfica & 2010 & Revisão \\
\hline $\begin{array}{l}\text { Práticas de enfermeiros } \\
\text { na gerência do cuidado } \\
\text { em enfermagem e } \\
\text { saúde: revisão } \\
\text { integrativa }\end{array}$ & $\begin{array}{l}\text { Revisão Integrativa da } \\
\text { Literatura }\end{array}$ & 2013 & Revisão \\
\hline
\end{tabular}

Com base na leitura sistemática do material, foi possível traçar dois pontos de inteligibilidade para os aspectos gerenciais do enfermeiro. Os mesmos são:

Categoria 1. O perfil do enfermeiro gestor; e Categoria 2. As dificuldades de gestão na atualidade. 
No que se refere a primeira categoria de análise, é possível perceber que o perfil do enfermeiro gestor está inserido em suas competências gerenciais, demonstrada através de suas ações, atitudes e habilidades diárias. Para Além de suas atividades específicas do profissional enfermeiro, é preciso apreciar e desenvolver habilidades administrativas, os conhecimentos devem ir além do conhecimento técnico - cientifico, deve envolver saber sócio-político e sócio- educativo.

Conforme aponta Ruthes etal (2007), a competência não é um estado ou um conhecimento que se tem e nem é resultado de treinamento. Competência, é na verdade, colocar em prática o que se sabe em um determinado contexto.

Assim, em termos de perfil, o enfermeiro gestor tem papel importante no planejamento, organização, gerenciamento e avaliação do processo de trabalho em enfermagem. Tais perspectivas são endógenas e exógenas, o que supõe que o mesmo deva estar preparado para trabalhar com conflitos, dialogar, negociar, prover estratégias capazes de interagir com a equipe, paciente e acompanhante. Assim, pode proporcionar maior qualidade do cuidado e da prestação de serviço.

Compreende-se então que não basta apenas capacitação profissional e competência técnica, mas criatividade, entusiasmo, inovação, intuição, emoção, disponibilidade, capacidade de relacionamento e principalmente comprometimento e responsabilidade com o processo de gestão.

Como sugere Santos (2013, p. 74):

\begin{abstract}
A gerência do cuidado realizada pelo enfermeiro relaciona-se diretamente à busca pela qualidade assistencial e de melhores condições de trabalho, por meio de ações como: realização do cuidado, gerência de recursos humanos e materiais, liderança, planejamento da assistência, capacitação da equipe de enfermagem, coordenação da produção do cuidado e avaliação das ações de enfermagem, está diretamente relacionada à busca pela qualidade assistencial e de melhores condições de trabalho para os profissionais.
\end{abstract}

Quanto a segunda Categoria de análise, as dificuldades no mercado de trabalho para o enfermeiro gestor, é possível perceber que, mesmo com o avanço nas três ultimas décadas onde foi possível acompanhar o desenvolvimento da enfermagem na prática assistencial e na produção cientifica, a área gerencial ainda sofre algumas opressões. A literatura demonstra que muitas instituições ainda não se deram conta da importância e necessidade de ter o enfermeiro como gestor, com isso a sobrecarga de ter apenas um profissional para desenvolver atividades assistencial e gerencial, faz com que haja uma qualidade de trabalho prejudicadas.

Considerando que o cuidado figura núcleo da competência e parte constituinte da equipe, desse modo, o maior percentual do capital humano de uma organização de saúde é responsável pela prática assistencial e gerencial de enfermagem (RUTHES etal 2009).

É preciso rever modelos de gestão e compor intervenções necessárias, as empresas devem disponibilizar de capital humano, começar a pensar em seus colaboradores como peças principais do processo, desta maneira os objetivos serão atingidos. Dentro das propostas esperadas estão: 
Desenvolvimento da liderança nos grupos de trabalho, inovação operacional, atendimento com qualidade ao cliente, satisfação ao cliente e acompanhantes, redução de custos, auditorias com o objetivo de dar apoio às ações educativas, gerência participativa e visão global.

As tendências e propostas para a gerência de enfermagem só serão alicerçadas quando as instituições compreender que administrar faz parte do cuidar e que gerenciamento produtivo baseiase em respeito, confiança e valorização de pessoas. Assim, é possível perceber os processos de gestão que o enfermeiro desenvolve em seu local de trabalho, e a destacável contribuição para conhecimento e crescimento destes profissionais e de suas respectivas instituições.

\section{Considerações Finais}

Embora claramente foi possível perceber a pouca produção bibliográfica que tenha como foco o gestor enfermeiro, especialmente no contexto hospitalar, o estudo proporcionou o conhecimento acerca das competências gerenciais do enfermeiro.

Foi possível observar também que a implantação destas competências gerenciais estabelece uma relação mutua entre organização e o profissional, a valorização de pessoas e a oferta de condições de trabalho só têm aumentado e qualificado o desenvolvimento da organização e a satisfação profissional. Desta maneira a satisfação não se resume só a de forma intra e inter equipes, mas deve levar em consideração que o cliente/usuário do SUS passa a ser o principal beneficiado, e as instituições contam com melhoria, qualidade e eficácia dos serviços prestados.

Faz-se necessário, com vistas ao maior desenvolvimento do conhecimento científico, que haja uma ampliação dos recortes de pesquisa. Além disso, é interessante que novos estudos se baseiem na coleta de dados em campo, com a realização de pesquisas quanti-qualitativas sobre o processo de gestão na enfermagem.

\section{Referências}

CERVO, A. L.; BERVIAN, P.A. Metodologia Científica. 5.ed. São Paulo: Prentice hall.2002.

FURUKAWA, Patrícia de Oliveira e CUNHA, Isabel Cristina Kowal Olm. Da gestão por competências às competências gerenciais do enfermeiro. Revista Brasileira de Enfermagem. [online]. 2010, vol.63, n.6, pp. 1061-1066. ISSN 0034-7167.

GIL, A. C. Como elaborar projeto de pesquisa. 4ed. São Paulo: Atlas,2002.

HARADA, Maria de Jesus Castro Souza; Gestão em Enfermagem: Ferramenta para Prática Segura. São Caetano do Sul, SP: Yends Editora. 2011. 
MINAYO, Maria Cecília de Souza. Pesquisa social: teoria, método e criatividade. 23. Ed. Petrópolis, RJ: Vozes, 2004.

RUTHES, Rosa Maria and Cunha, Isabel Cristina Kowal Olm. Competências do enfermeiro na gestão do conhecimento e capital intelectual. Revista Brasileira de Enfermagem. Dez 2009, vol.62, no.6, p.901-905. ISSN 0034-7167

RUTHES, Rosa Maria and Cunha, Isabel Cristina Kowal Olm. Entendendo as competências para aplicação na enfermagem. Revista Brasileira de Enfermagem. Fev 2007, vol.61, no.1, p.109-112. ISSN 0034-7167

SANTOS, José Luís Guedes dos et al. Práticas de enfermeiros na gerência do cuidado em enfermagem e saúde: revisão integrativa. Revista Brasileira de Enfermagem. Abr 2013, vol.66, no.2, p.257-263.ISSN 0034-7167

SELLTIZ, C. ET AL. Métodos de pesquisas nas relações sociais. São Paulo: Herder, 1987.

TRIVINOS, A.N.S. Introdução à pesquisa em Ciências Sociais: a pesquisa qualitativa em educação. São Paulo: Atlas, 1987.

\section{Como citar este artigo (Formato ABNT):}

MELO, A.; VIEIRA, S.S. O Enfermeiro frente as competências gerenciais na gestão à saúde: uma pesquisa bibliográfica. Id on Line Revista de Psicologia, Novembro de 2015, vol.9, n.28, p. 71-77. ISSN 1981-1189.

Recebido: 08/05/2015

Aceito:18/05/2015 